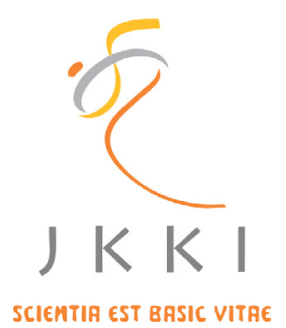

Jurnal Kedokteran dan Kesehatan Indonesia

\author{
Indonesian Journal of Medicine and Health
}

Journal homepage : https://journal.uii.ac.id/JKKI

\title{
Medical biofilms: The killer
}

Sufi Desrini*1

${ }^{1}$ Department of Pharmacology, Faculty of Medicine, Universitas Islam Indonesia, Yogyakarta, Indonesia

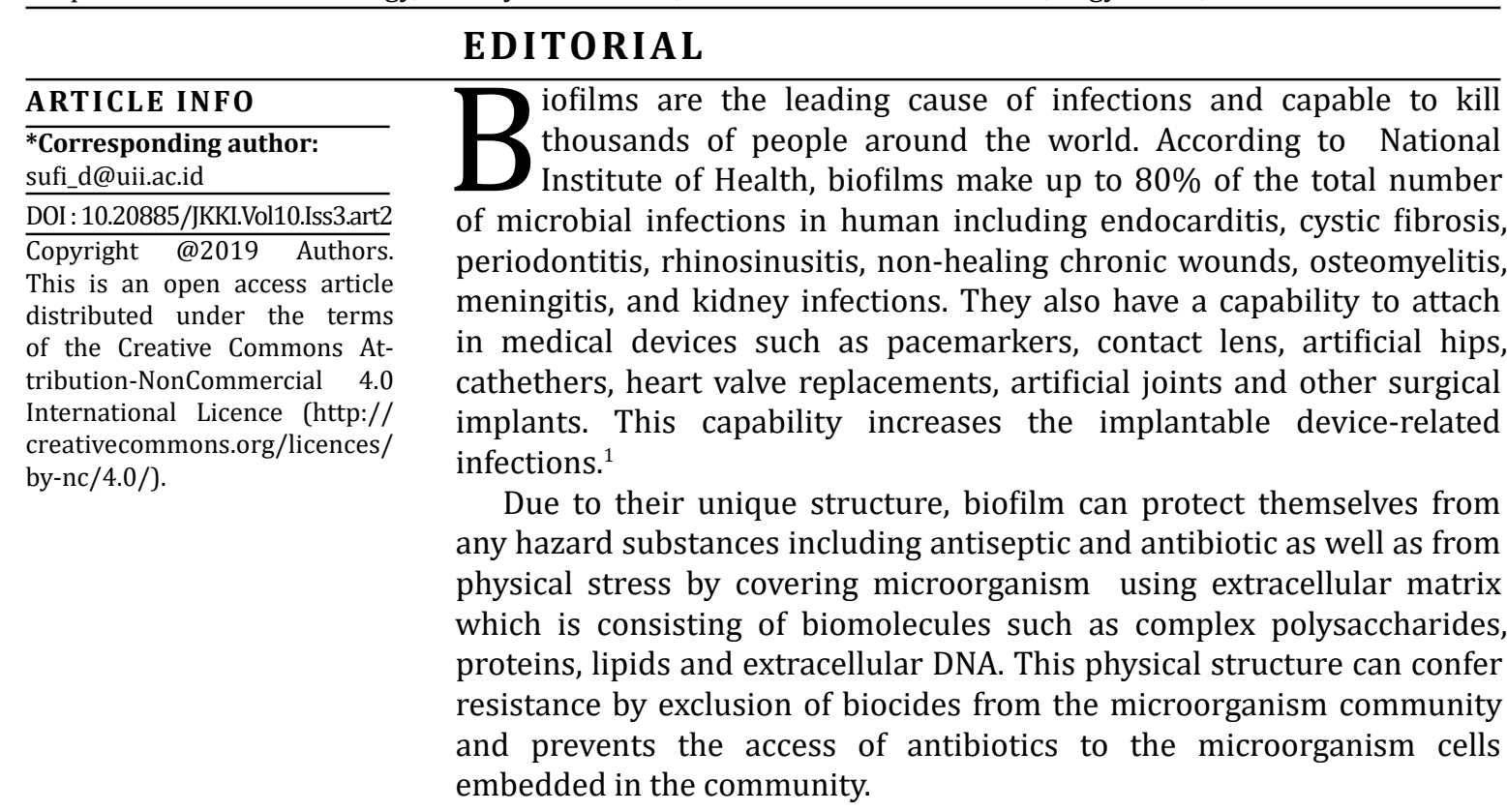

As a community, biofilms also make a social interaction process between cells by secretion of small signalling molecules which is known as autoinducers This interaction process has been known as Quorum sensing (QS). ${ }^{2}$ Autoinducers secreted into the environment will gradually increase in concentration as the microorganism population grows. This process gives many profits to microorganism in host colonization, creation of biofilms, defense against competitors, and adaptation to changing environments. Indeed, pathogenic microorganism in biofilms exploit QS process to trigger virulence and create antibiotic resistance.

Many strategies to control biofilms have been implied ranging from conventional approaches such as removing the indwelling medical equipment followed by replacement with new ones and combating by antibiotics to novel approaches such as using a synergistic effect of antimicrobial photodynamic therapy and various antimicrobial and antibiofilm combination, coating surgical implants, and developing antibiofilm through medical plants. ${ }^{3}$ The principal of antibiotic therapy in order to treat biofilms is antibiotic should be validly selected on the basis of sensitivity and the capacity to penetrate properly through the biofilm matrix. ${ }^{4}$ Well-known the stages of biofilm in clinical conditions might be help to overcome biofilm by using antibiotics.

Which is the best strategies? Unfortunately, until now there is still no information about the significant reduce of biofilm-related infections. Each strategy to control biofilm still has limitation. The removal of the implant or other medical devices could increase a trauma to the patient and the cost of treatment. Exploring new antibiotics from natural product is still lack and takes times to get a new lead compound. However, it is argue to keep 'on the way' in order to find the best solutions. More actions need to be involved to control and combat biofilms. 


\section{REFERENCES}

1. Khatoon Z, McTiernan CD, Suuronen EJ, Mah TF, Alarcon EI. Bacterial biofilm formation on implantable devices and approaches to its treatment and prevention. Heliyon. 2018;4(12):e01067.

2. Singh S, Singh SK, Chowdhury I, Singh R. Understanding the Mechanism of Bacterial Biofilms Resistance to Antimicrobial Agents. Open Microbiology Journal . 2017;11(1):53-62.

3. Roy R, Tiwari M, Donelli G, Tiwari V. Strategies for combating bacterial biofilms: A focus on anti-biofilm agents and their mechanisms of action. Virulence. 2018;9(1):522-54.

4. Wu H, Moser C, Wang HZ, Høiby N, Song ZJ. Strategies for combating bacterial biofilm infections. International journal of oral science. 2015;7:1-7. 